\title{
Neuroprotective Effects of Phlorotannin-Rich Extract from Brown Seaweed Ecklonia cava on Neuronal PC-12 and SH-SY5Y Cells with Oxidative Stress
}

\author{
Jin Ah Nho ${ }^{1 \dagger}$, Yong Sub Shin ${ }^{2 \dagger}$, Ha-Ram Jeong ${ }^{2}$, Suengmok Cho ${ }^{3}$, Ho Jin Heo ${ }^{4}$, Gun Hee Kim ${ }^{5}$, and Dae-Ok Kim ${ }^{1,2 *}$ \\ ${ }^{1}$ Department of Food Science and Biotechnology, Kyung Hee University, Yongin 17104, Republic of Korea \\ ${ }^{2}$ Graduate School of Biotechnology, Kyung Hee University, Yongin 17104, Republic of Korea \\ ${ }^{3}$ Department of Food Science and Technology, Pukyong National University, Busan 48513, Republic of Korea \\ ${ }^{4}$ Division of Applied Life Science (BK21 Plus), Institute of Agricultural and Life Science, Gyeongsang National University, Jinju 52828, \\ Republic of Korea \\ ${ }^{5}$ Department of Foods and Nutrition, Duksung Women's University, Seoul 01369, Republic of Korea
}

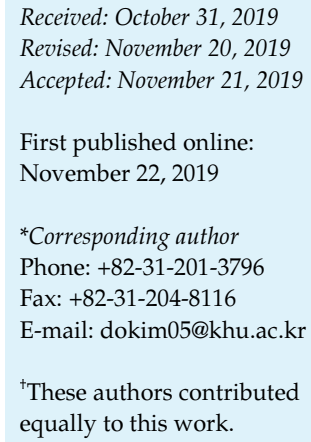

Neurodegenerative disorders in the elderly are characterized by gradual loss of memory and cognitive function. Oxidative stress caused by reactive oxygen species is associated with progressive neuronal cell damage and death in Alzheimer's disease, one of the most common neurodegenerative disorders. An edible brown seaweed, Ecklonia cava, contains a variety of biologically active compounds such as phlorotannins. In this study, we comparatively evaluated the total phenolic content, antioxidant capacity, and neuroprotective effects of the phlorotannin-rich extract from E. cava (PEEC). The total phenolic content of PEEC and dieckol was $810.8 \mathrm{mg}$ gallic acid equivalents (GAE)/g and $996.6 \mathrm{mg} \mathrm{GAE} / \mathrm{g}$, respectively. Antioxidant capacity of PEEC was 1,233.8 mg vitamin C equivalents (VCE)/g and $392.1 \mathrm{mg} \mathrm{VCE} / \mathrm{g}$ determined using ABTS and DPPH assays, respectively, while those of dieckol were 2,238.4 mg VCE/g and $817.7 \mathrm{mg} \mathrm{VCE} / \mathrm{g}$. High-performance liquid chromatography results revealed $48.08 \pm 0.67 \mathrm{mg}$ dieckol/g of PEEC. PEEC had neuroprotective effects in pheochromocytoma (PC-12) and human neuroblastoma (SH-SY5Y) cells against $\mathrm{H}_{2} \mathrm{O}_{2}$ - and AAPH-induced oxidative damage, partly due to reduced intracellular oxidative stress. PEEC treatment inhibited acetylcholinesterase and butyrylcholinesterase in a dose-dependent manner. Taken together, these findings suggest that PEEC is a good source of antioxidants and neuroprotective materials.

Keywords: Cholinesterase, dieckol, neuron, neuroprotection, vitamin C equivalent antioxidant capacity

\section{Introduction}

Alzheimer's disease (AD) is a neurodegenerative disease of the elderly characterized by memory deficits and cognitive impairments due to progressive degeneration and/or death of neurons in the brain [1,2]. As the average life span increases, so does the number of people with dementia. According to World Health Organization statistics [3], the total number of people with dementia is estimated to increase to 82 million by 2030 and 152 million by 2050 . Drugs such as donepezil, galantamine, memantine, and rivastigmine may slow progress of $\mathrm{AD}$ but are not cures. Furthermore, usage of these drugs is limited due to side effects such as nausea and vomiting. Thus, continuous research and discovery of natural drugs for prevention and treatment of AD are necessary.

Oxidative stress, an imbalance between the generation and elimination of reactive oxygen species (ROS), produces an 
excessive amount of free radicals and oxidants in the body [4]. Excessive production of ROS, such as hydroxyl radicals, hydrogen peroxide, superoxide, and hypochlorous acid, causes oxidative damage to cellular macromolecules such as DNA, proteins, and lipids and impairs mitochondrial function [5]. Oxidative stress is associated with neuronal cell damage and death in neurodegenerative diseases such as $\mathrm{AD}$, Huntington's disease, and Parkinson's disease [6]. The brain is particularly vulnerable to oxidative stress due to high levels of polyunsaturated fatty acids, low levels of antioxidants, and high oxygen consumption [7]. Excess exposure of the brain to oxidative stress can damage neuronal structures, leading to loss of neurons. Strategically, dietary antioxidants are recommended for prevention and/or delay of neurodegeneration caused by oxidative stress [8]. The neurotransmitter acetylcholine is hydrolyzed to choline and acetate by acetylcholinesterase (AChE), terminating acetylcholine-mediated neurotransmission [9]. Butyrylcholinesterase $(\mathrm{BChE})$ is a hydrolase found in cholinergic neurons in the nervous system of the human brain and also hydrolyzes acetylcholine to choline and acetate [10]. Levels of $\mathrm{AChE}$ and $\mathrm{BChE}$ in the brain are increased in Alzheimer's disease [10]. Therefore, reversible inhibitors of $\mathrm{AChE}$ and $\mathrm{BChE}$ can potentially maintain the levels of the neurotransmitter acetylcholine by inhibiting their activities in AD patients. Research on various natural antioxidants, including phenolics and vitamins, has mainly focused on terrestrial plants such as herbs, fruits, and vegetables [11]. However, relatively limited information is available about the neuroprotective effects of natural antioxidants and cholinesterase inhibitors derived from marine resources.

Ecklonia cava (EC), an edible brown seaweed, is distributed on the southern coast of the Korean Peninsula. EC contains a variety of bioactive compounds, such as phlorotannins, peptides, carotenoids, and fucoidans [12, 13]. Phlorotannins, a type of tannin found in brown algae, are polymers composed of a phloroglucinol (1,3,5-trihydroxybenzene) monomer unit with varying degrees of polymerization and bonding [14]. Phlorotannins from EC formed as secondary phenolic metabolites include dieckol, phlorofucofuroeckol, 6,6'-bieckol, and eckol [15]. Phlorotannins have been reported to have a variety of beneficial properties, including antioxidant, anti-inflammatory, anti-allergic [16], anti-diabetic [17], hypnotic [18], and neuroprotective effects [19, 20].

Studies have reported diverse neuroprotective effects of marine algae EC [19, 20], but limited research has assessed the neuroprotective effects of phlorotannins in EC. In this study, we investigate total phenolic content, antioxidant capacity, and neuroprotective effects of phlorotannin-rich extract from EC (PEEC) and dieckol against oxidative stress in rat pheochromocytoma (PC-12) and human neuroblastoma (SH-SY5Y) cells. Anticholinesterase activity of PEEC and dieckol was also examined using $\mathrm{AChE}$ and $\mathrm{BChE}$ inhibition assays. High-performance liquid chromatography (HPLC) was used to quantify dieckol, a phlorotannin in PEEC.

\section{Materials and Methods}

\section{Chemicals}

Acetylthiocholine iodide (ATCI), AChE, ascorbic acid, 2,2'-azinobis(3-ethylbenzothiazoline-6-sulfonic acid) diammonium salt (ABTS), 2,2'-azobis(2-methylpropionamidine) dihydrochloride (AAPH), BChE, S-butyrylthiocholine chloride (BTCC), 2',7'-dichlorofluorescin diacetate (DCFH-DA), dimethyl sulfoxide (DMSO), 3-(4,5dimethyl-2-thiazolyl)-2,5-diphenyl-2H-tetrazolium bromide (MTT), 2,2-diphenyl-1-picrylhydrazyl (DPPH), 5,5'-dithiobis(2-nitrobenzoic acid) (DTNB), Folin-Ciocalteu's phenol reagent, gallic acid, hydrogen peroxide, and phosphate-buffered saline (PBS) were purchased from Sigma-Aldrich Co., LLC (USA). Dulbecco's phosphate-buffered saline (DPBS), fetal bovine serum (FBS), Hanks' balanced salt solution (HBSS), Minimum Essential Medium Eagle (MEM), penicillin-streptomycin solutions, Roswell Park Memorial Institute (RPMI)-1640, and trypsin-EDTA were purchased from Welgene Inc. (Korea). Dieckol, a standard compound isolated from the phlorotannin-rich extract using silica gel and Sephadex LH-20 column chromatography [21], was obtained from S\&D Co., Ltd. (Korea). All reagents were of analytical or HPLC grade unless otherwise specified.

\section{PEEC Preparation}

PEEC was supplied by Seojin Biotech Co., Ltd. (Republic of Korea). EC was collected from Aewol-eup, Jeju-island, Republic of Korea. Fresh EC was washed with distilled water and dried. Dry EC was extracted with 10 multiples of $50 \%(\mathrm{v} / \mathrm{v})$ fermentation ethanol at $60^{\circ} \mathrm{C}$ for $6 \mathrm{~h}$. The extract was filtered through Whatman no. 2 filter paper (Whatman International Ltd., England), concentrated, and then lyophilized.

\section{Determination of Total Phenolic Content}

Total phenolic content was measured with a colorimetric assay using Folin-Ciocalteu's phenol reagent [22]. An aliquot $(0.2 \mathrm{ml})$ of appropriately diluted PEEC or dieckol was mixed with $2.6 \mathrm{ml}$ of deionized water. At $0 \mathrm{~min}, 0.2 \mathrm{ml}$ of Folin-Ciocalteu's phenol reagent was added to the mixture. At $6 \mathrm{~min}, 2 \mathrm{ml}$ of $7 \%(\mathrm{w} / \mathrm{v})$ $\mathrm{Na}_{2} \mathrm{CO}_{3}$ solution was added. At $90 \mathrm{~min}$, absorbance was measured at $750 \mathrm{~nm}$ using a SPECTRONIC 200 spectrophotometer (Thermo Fisher Scientific Inc., USA). Total phenolic content was expressed as mg gallic acid equivalents (GAE)/g. 


\section{Determination of Antioxidant Capacity}

Antioxidant capacity was measured using ABTS and DPPH radicals and expressed as $\mathrm{mg}$ vitamin $\mathrm{C}$ equivalents (VCE)/g. In the ABTS radical scavenging assay [23], ABTS radical solution was adjusted to an absorbance of $0.650 \pm 0.020$ at $734 \mathrm{~nm}$. The reaction between ABTS radicals and appropriately diluted PEEC or dieckol was allowed to proceed at $37^{\circ} \mathrm{C}$ for $10 \mathrm{~min}$, and the absorbance of the resulting solution was measured at $734 \mathrm{~nm}$ using a SPECTRONIC 200 spectrophotometer (Thermo Fisher Scientific Inc.).

In the DPPH radical scavenging assay [24], DPPH radicals $(0.1 \mathrm{mM})$ were dissolved in $80 \%(\mathrm{v} / \mathrm{v})$ aqueous methanol. Absorbance of DPPH radicals was set to $0.650 \pm 0.020$ at $517 \mathrm{~nm}$. The reaction between DPPH radicals and the appropriately diluted PEEC or dieckol was allowed to proceed at $23^{\circ} \mathrm{C}$ for $30 \mathrm{~min}$. The absorbance of the resulting solution was monitored at $517 \mathrm{~nm}$ using a SPECTRONIC 200 spectrophotometer (Thermo Fisher Scientific Inc.).

\section{Quantification of Dieckol in PEEC using Reversed-Phase HPLC System}

The amount of dieckol in PEEC was analyzed using a reversedphase HPLC system (Agilent 1200; Agilent Technologies, Inc., USA) equipped with quaternary pump, autosampler, vacuum degasser, thermostatted column compartment, and diode array detector. Chromatographic separation was performed using a C18 reversed-phase analytical column (Kromasil 100-5-C18, $4.6 \times$ $250 \mathrm{~mm}, 5 \mu \mathrm{m}$; Eka Chemicals AB, Sweden) with injection volume of $5 \mu \mathrm{l}$. The flow rate was maintained at $0.7 \mathrm{ml} / \mathrm{min}$. The detection wavelength was $230 \mathrm{~nm}$. The gradient of two mobile phases, deionized water (solvent $\mathrm{A}$ ) and absolute methanol (solvent $\mathrm{B}$ ), was as follows; $80 \% \mathrm{~A} / 20 \% \mathrm{~B}$ at $0 \mathrm{~min}, 60 \% \mathrm{~A} / 40 \% \mathrm{~B}$ at $10 \mathrm{~min}$, $40 \% \mathrm{~A} / 60 \% \mathrm{~B}$ at $40 \mathrm{~min}, 20 \% \mathrm{~A} / 80 \% \mathrm{~B}$ at $45 \mathrm{~min}, 80 \% \mathrm{~A} / 20 \% \mathrm{~B}$ at $55 \mathrm{~min}$, and $80 \% \mathrm{~A} / 20 \% \mathrm{~B}$ at $60 \mathrm{~min}$. Dieckol in PEEC was quantified using the standard curve of authentic standard dieckol.

\section{Cell Culture}

Two neuronal cell lines (PC-12 and SH-SY5Y) were used to evaluate the neuroprotective effects of PEEC and dieckol against oxidative stress in vitro. The PC-12 cell line is derived from a transplantable rat pheochromocytoma and was purchased from American Type Culture Collection (USA). PC-12 cells were cultured in RPMI-1640 medium containing 10\% heat-inactivated FBS, 100 units $/ \mathrm{ml}$ penicillin, and $100 \mu \mathrm{g} / \mathrm{ml}$ streptomycin. The human neuroblastoma SH-SY5Y cell line was obtained from the Korean Cell Line Bank (Korea). SH-SY5Y cells were cultured in MEM containing 10\% heat-inactivated FBS, 100 units $/ \mathrm{ml}$ penicillin, and $100 \mu \mathrm{g} / \mathrm{ml}$ streptomycin. Both neuronal cell lines were cultured in a humidified incubator $\left(\mathrm{CO}_{2}\right.$ incubator BB 15; Thermo Electron LED GmbH, Germany) with $5 \% \mathrm{CO}_{2}$ at $37^{\circ} \mathrm{C}$.

\section{Cytotoxicity and Cell Viability}

The effects of PEEC and dieckol on the cytotoxicity and cell viability of both PC-12 and SH-SY5Y cell lines were estimated using MTT reduction assay [25]. PC-12 cells at a density of $2 \times$ $10^{4}$ cells/well in 96-well plates were pre-cultured for $24 \mathrm{~h}$. After removal of the medium, PC-12 cells were treated with serum-free medium containing various concentrations of PEEC and dieckol for $24 \mathrm{~h}$. PC-12 cells were treated with $300 \mu \mathrm{M} \mathrm{H}_{2} \mathrm{O}_{2}$ for $1 \mathrm{~h}$ and then with $0.5 \mathrm{mg} / \mathrm{ml}$ MTT for $3 \mathrm{~h}$. Conversely, SH-SY5Y cells in 96-well plates at a density of $1 \times 10^{5}$ cells/well were pre-cultured for $24 \mathrm{~h}$. After removal of the medium, SH-SY5Y cells were treated with serum-free medium containing various concentrations of PEEC and dieckol for $24 \mathrm{~h}$. After $24 \mathrm{~h}$, SH-SY5Y cells were treated with $100 \mu \mathrm{M} \mathrm{H}_{2} \mathrm{O}_{2}$ for $1 \mathrm{~h}$, and then with $0.5 \mathrm{mg} / \mathrm{ml}$ MTT for $3 \mathrm{~h}$. The resulting formazan products from both cell lines were dissolved by addition of DMSO. The amount of MTT formazan dissolved in DMSO was determined by measuring absorbance with a microplate reader (Infinite M200; Tescan Austria GmbH) at $570 \mathrm{~nm}$ (detection wavelength) and $630 \mathrm{~nm}$ (reference wavelength). The cytotoxicity and viability of both cell lines were expressed as percentage (\%) of viable cells relative to control cells $(100 \%)$.

\section{Determination of Intracellular Oxidative Stress Level}

Intracellular oxidative stress level was evaluated using the fluorescent probe DCFH-DA [26]. PC-12 $\left(2 \times 10^{4}\right.$ cells/well $)$ and SH-SY5Y $\left(1 \times 10^{5}\right.$ cells/well $)$ cells were pre-cultured for $24 \mathrm{~h}$. This was followed by treatment with various concentrations of PEEC and dieckol for $24 \mathrm{~h}$. After removing the supernatant, both cell lines were incubated with $50 \mu \mathrm{M}$ of DCFH-DA in HBSS for $1 \mathrm{~h}$. PC-12 cells were separately treated with $30 \mu \mathrm{M}$ of AAPH and $100 \mu \mathrm{M}$ of $\mathrm{H}_{2} \mathrm{O}_{2}$ in HBSS for $1 \mathrm{~h}$, while SH-SY5Y cells were separately treated with $10 \mu \mathrm{M}$ of AAPH and $100 \mu \mathrm{M}$ of $\mathrm{H}_{2} \mathrm{O}_{2}$ in HBSS for $1 \mathrm{~h}$. Fluorescence was measured at $485 \mathrm{~nm}$ (detection wavelength) and $535 \mathrm{~nm}$ (emission wavelength) using a microplate reader (Infinite M200; Tecan Austria $\mathrm{GmbH}$ ). The intracellular oxidative stress level was expressed as percentage (\%) decrease in fluorescence intensity compared to the control (100\%).

\section{Inhibitory Effects on Cholinesterases}

Inhibitory effects of PEEC and dieckol on cholinesterases (AChE and BChE) were assessed by a modified method of Ellman et al. [27]. To evaluate AChE inhibition, $20 \mu \mathrm{l}$ of PEEC or dieckol at various concentrations was mixed with $150 \mu$ of DPBS. At zero min, $20 \mu \mathrm{l}$ of $15 \mathrm{mM}$ ATCI and $30 \mu \mathrm{l}$ of $10 \mathrm{mM}$ DTNB were added to the mixture. After incubation at $37^{\circ} \mathrm{C}$ for $10 \mathrm{~min}, 20 \mu \mathrm{l}$ of $\mathrm{AChE}$ $(0.2 \mathrm{U} / \mathrm{ml})$ was added. After reaction at $37^{\circ} \mathrm{C}$ for $30 \mathrm{~min}$, absorbance was measured at $415 \mathrm{~nm}$ using a microplate reader (Infinite M200; Tecan Austria $\mathrm{GmbH}$ ). BChE inhibition was evaluated by adding $20 \mu \mathrm{l}$ of BTCC $(10 \mathrm{mM})$ and $20 \mu \mathrm{l}$ of BChE $(0.06 \mathrm{U} / \mathrm{ml})$ instead of ATCI and AChE. The percentage (\%) inhibition of $\mathrm{AChE}$ and $\mathrm{BChE}$ was calculated using the equation

$$
\text { Percentage }(\%) \text { inhibition }=\left(\left[A_{\text {control }}-A_{\text {sample }}\right] / A_{\text {control }}\right) \times 100
$$

where $A_{\text {control }}$ is absorbance of the control at $30 \mathrm{~min}$, and $A_{\text {sample }}$ is absorbance of the sample at $30 \mathrm{~min}$. 
Table 1. Total phenolic content and antioxidant capacity of the phlorotannin-rich extract from Ecklonia cava (PEEC) and dieckol.

\begin{tabular}{lccc}
\hline & $\begin{array}{c}\text { Total phenolic content } \\
\text { (mg gallic acid } \\
\text { equivalents } / \mathrm{g})\end{array}$ & \multicolumn{2}{c}{$\begin{array}{c}\text { Antioxidant capacity } \\
\text { (mg vitamin C equivalents/g) }\end{array}$} \\
\cline { 3 - 4 } & $810.8 \pm 19.4^{3}$ & $\mathrm{ABTS}^{1}$ & $\mathrm{DPPH}^{2}$ \\
\hline PEEC & $996.6 \pm 34.2$ & $2,233.8 \pm 8.2$ & $392.1 \pm 5.8$ \\
Dieckol & & &
\end{tabular}

${ }^{1} 2,2$ '-Azino-bis(3-ethylbenzothiazoline-6-sulphonic acid) radical scavenging assay

${ }^{2}$ 2,2-Diphenyl-1-picrylhydrazyl radical scavenging assay

${ }^{3}$ Data are expressed as mean \pm standard deviation $(n=3)$.

\section{Statistical Analysis}

Data are expressed as mean \pm standard deviation of three replicate determinations. One-way analysis of variance was applied to determine the significance of differences among means. Statistical analyses were conducted using Duncan's multiple range test using SAS software (version 9.4; SAS Institute Inc., USA) with significance set to $p<0.05$.

\section{Results}

\section{Total Phenolic Content and Antioxidant Capacity}

Total phenolic content and antioxidant capacity of PEEC and dieckol are shown in Table 1 . The total phenolic content of PEEC and dieckol was $810.8 \mathrm{mg}$ GAE/g and $996.6 \mathrm{mg} \mathrm{GAE} / \mathrm{g}$, respectively. Antioxidant capacity of PEEC was 1,233.8 $\mathrm{mg} \mathrm{VCE} / \mathrm{g}$ and $392.1 \mathrm{mg} \mathrm{VCE} / \mathrm{g}$ as determined using ABTS and DPPH assays, respectively. Dieckol showed antioxidant capacity of 2,238.4 mg VCE/g with ABTS assay and $817.7 \mathrm{mg}$ VCE/g with DPPH assay.

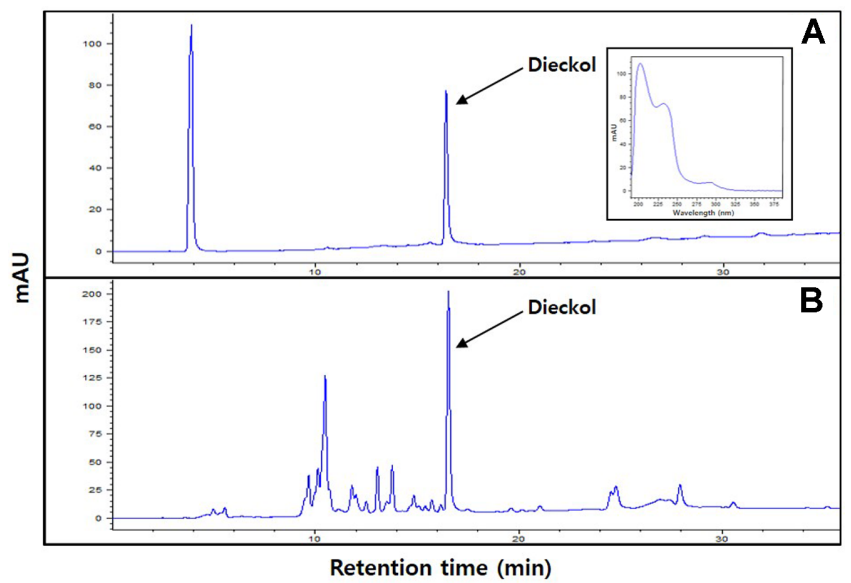

Fig. 1. HPLC traces of the (A) dieckol standard and (B) phlorotannin-rich extract from Ecklonia cava at $230 \mathrm{~nm}$.

\section{HPLC Analysis}

Using reversed-phase HPLC analysis, dieckol eluted at a $16.521 \mathrm{~min}$ retention time (Fig. 1). PEEC contained $48.08 \pm$ $0.67 \mathrm{mg}$ dieckol/g (data not shown).

\section{Neuroprotective Effects of PEEC and Dieckol against Oxidative Stress in Neurons}

The cytotoxicity of PEEC and dieckol was examined at various concentrations. Cell viability of $90 \%$ or above was considered lack of cell cytotoxicity. PEEC and dieckol had no cytotoxicity against PC-12 cells up to $62.5 \mu \mathrm{g} / \mathrm{ml}$ and $40.0 \mu \mathrm{g} / \mathrm{ml}$, respectively (data not shown). Treatment with
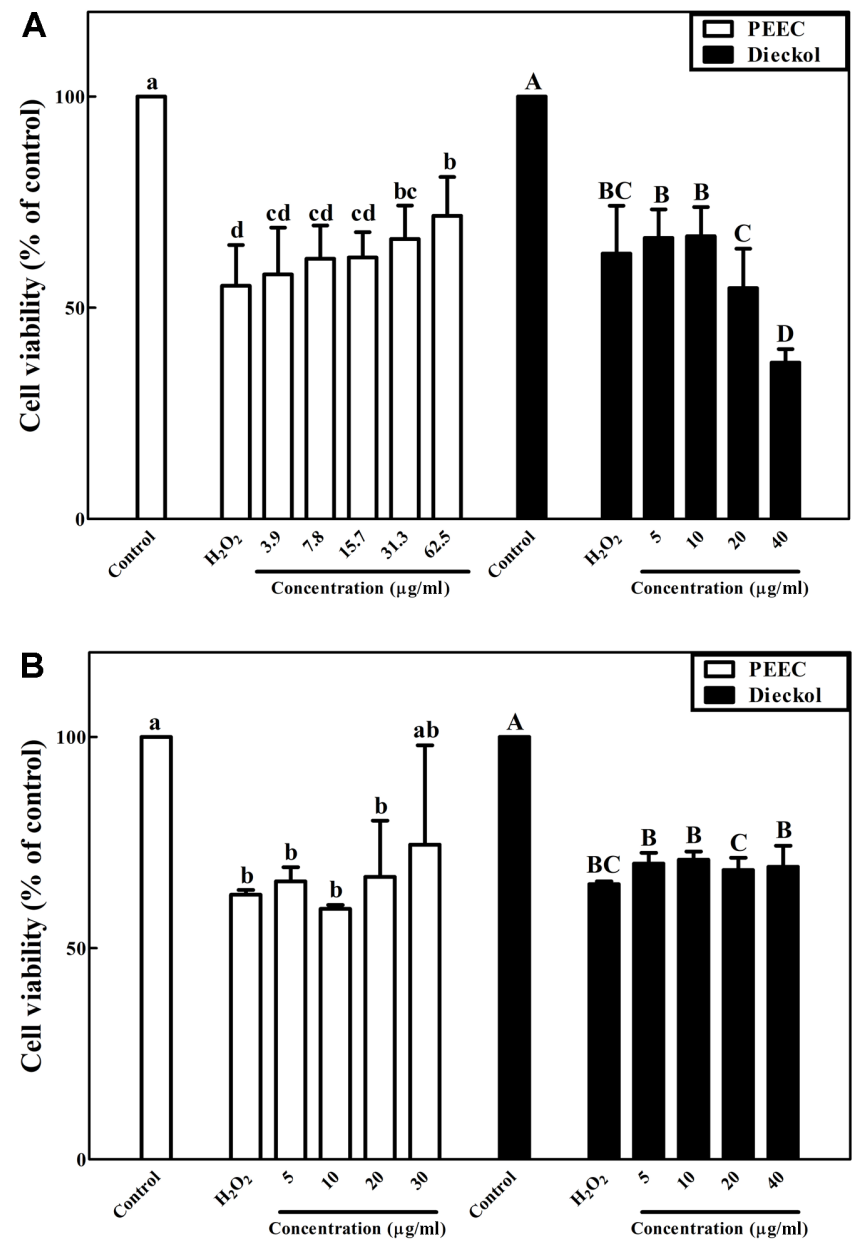

Fig. 2. Neuroprotective effects of the phlorotannin-rich extract from Ecklonia cava (PEEC) and dieckol on neuronal (A) PC-12 and (B) SH-SY5Y cells against oxidative stress induced with hydrogen peroxide $\left(\mathrm{H}_{2} \mathrm{O}_{2}\right)$ using the MTT assay.

Data are displayed as mean \pm standard deviation (bars) of three replicates. Different lowercase and uppercase characters on bars in PEEC and dieckol treatments indicate significant differences according to Duncan's multiple range test $(p<0.05)$. 
hydrogen peroxide at $300 \mu \mathrm{M}$ resulted in approximately $38.2-44.8 \%$ decrease of cell viability in PC-12 cells compared with the control (100\%) (Fig. 2A). Pretreatment of PC-12 cells with PEEC increased the viability of PC-12 cells exposed to oxidative stress compared with the stress control (Fig. 2A). Treatment with PEEC of $62.5 \mu \mathrm{g} / \mathrm{ml}$ significantly $(p<0.05)$ increased PC-12 cell viability up to about $71.8 \%$ compared with the stress control $(55.2 \%)$ (Fig. 2A). However, treatment with dieckol had no significant $(p>0.05)$ effect compared with the stress control $(62.8 \%)$ (Fig. 2A).

Both PEEC and dieckol had no cytotoxicity against dopaminergic neuronal SH-SY5Y cells up to $30.0 \mu \mathrm{g} / \mathrm{ml}$ and $40.0 \mu \mathrm{g} / \mathrm{ml}$, respectively (data not shown). Oxidative
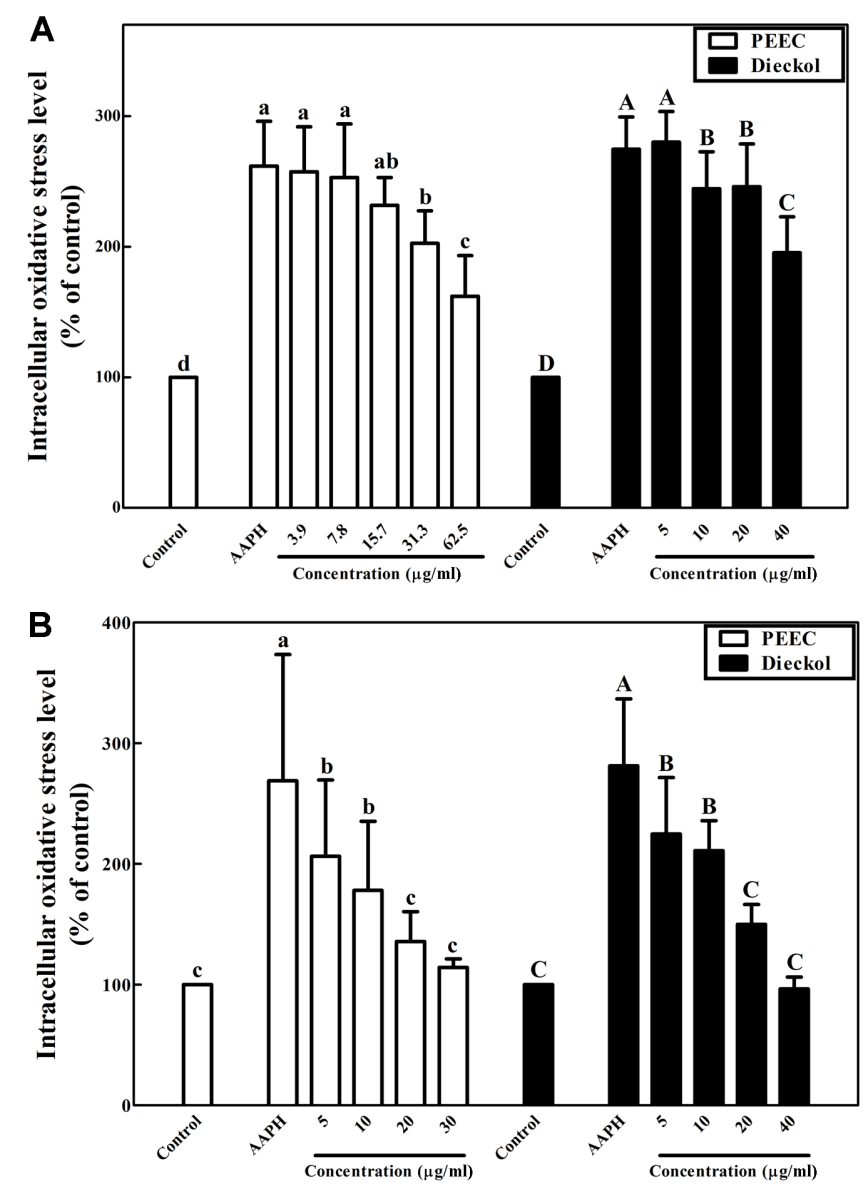

Fig. 3. Effects of the phlorotannin-rich extract from Ecklonia cava (PEEC) and dieckol on intracellular oxidative stress in neuronal (A) PC-12 and (B) SH-SY5Y cells against oxidative stress induced with AAPH using the DCFH-DA assay.

Data are displayed as mean \pm standard deviation (bars) of three replicates. Different lowercase and uppercase characters on bars in PEEC and dieckol treatments indicate significant differences according to Duncan's multiple range test $(p<0.05)$. stress $\left(100 \mu \mathrm{M} \mathrm{H}_{2} \mathrm{O}_{2}\right)$ reduced the viability of SH-SY5Y cells to approximately $62.7-65.2 \%$ compared with the control $(100 \%)$ (Fig. 2B). Pretreatment of cells with PEEC and dieckol resulted in no significant $(p>0.05)$ increase in viability of SH-SY5Y cells exposed to oxidative stress compared with the stress control (Fig. 2B).

\section{Intracellular Oxidative Stress}

We evaluated whether PEEC and dieckol reduce AAPHinduced oxidative stress in PC-12 and SH-SY5Y cells (Fig. 3). As shown in Fig. 3A, oxidative stress (261.8\%) following only AAPH treatment was attenuated to $162.1 \%$
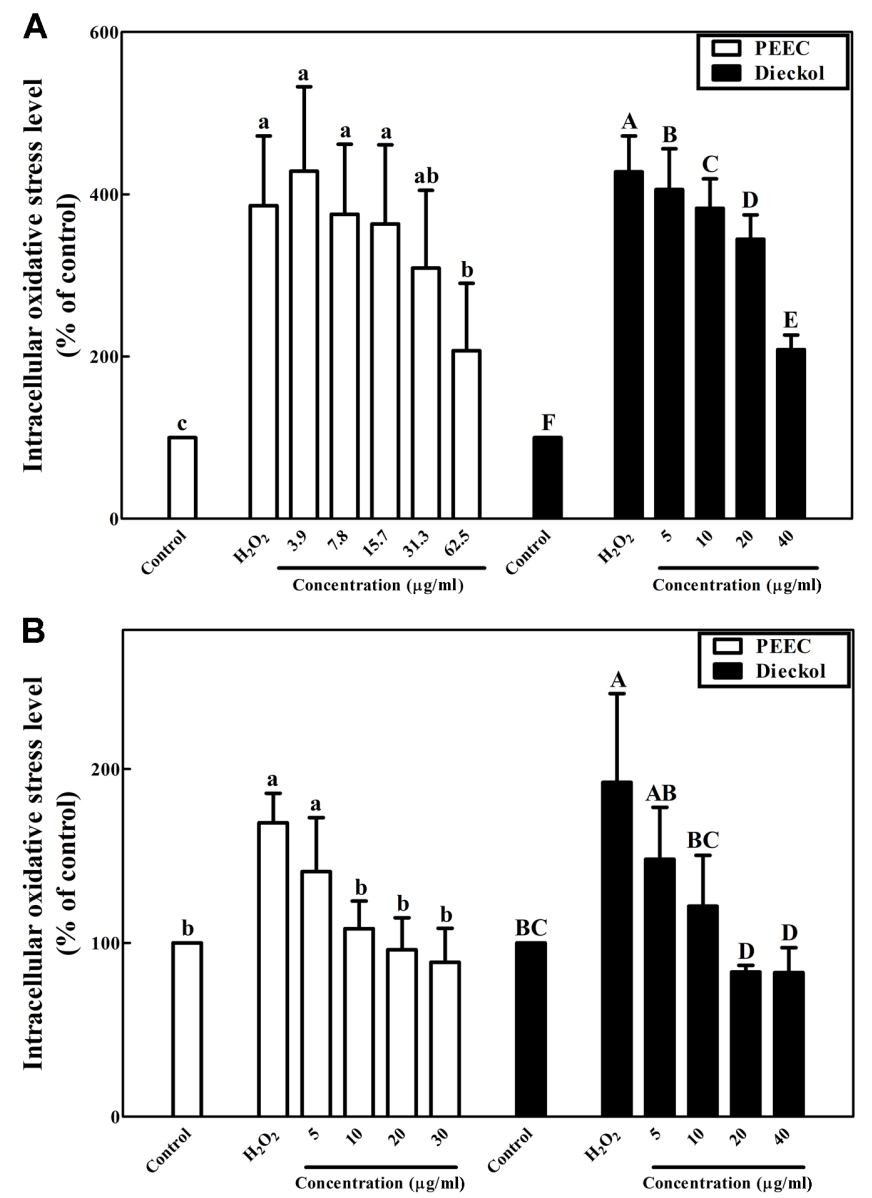

Fig. 4. Effects of the phlorotannin-rich extract from Ecklonia cava (PEEC) and dieckol on intracellular oxidative stress in neuronal (A) PC-12 and (B) SH-SY5Y cells against oxidative stress induced with hydrogen peroxide $\left(\mathrm{H}_{2} \mathrm{O}_{2}\right)$ using the DCFH-DA assay.

Data are displayed as mean \pm standard deviation (bars) of three replicates. Different lowercase and uppercase characters on bars in PEEC and dieckol treatments indicate significant differences according to Duncan's multiple range test $(p<0.05)$. 
after treatment with $62.5 \mu \mathrm{g} / \mathrm{ml}$ PEEC. Treatment with $40.0 \mu \mathrm{g} / \mathrm{ml}$ dieckol decreased oxidative stress to $195.4 \%$ compared to the stress control (274.7\%) treated with AAPH only. Exposure of SH-SY5Y cells to $10 \mu \mathrm{M}$ of AAPH increased intracellular oxidative stress level to approximately $270 \%$ (Fig. 3B). Treatment with $30.0 \mu \mathrm{g} / \mathrm{ml}$ PEEC and $40.0 \mu \mathrm{g} / \mathrm{ml}$ dieckol attenuated intracellular oxidative stress to $114.2 \%$ and $96.4 \%$ in SH-SY5Y cells, respectively (Fig. 3B).

We also evaluated whether PEEC and dieckol scavenge $\mathrm{H}_{2} \mathrm{O}_{2}$-induced oxidative stress in PC-12 and SH-SY5Y cells (Fig. 4). Exposure of PC-12 cells to $100 \mu \mathrm{M} \mathrm{H}_{2} \mathrm{O}_{2}$ increased the intracellular oxidative stress level up to $386.0 \%$ and $427.7 \%$ in treatments with PEEC and dieckol, respectively, whereas treatments with $62.5 \mu \mathrm{g} / \mathrm{ml}$ PEEC and $40.0 \mu \mathrm{g} / \mathrm{ml}$ dieckol attenuated intracellular oxidative stress to $207.1 \%$ and $208.1 \%$ (Fig. 4A). Exposure of SH-SY5Y cells to $100 \mu \mathrm{M}$ $\mathrm{H}_{2} \mathrm{O}_{2}$ showed intracellular oxidative stress levels of $169.1 \%$ and $192.3 \%$ in treatments with PEEC and dieckol, respectively, whereas treatments with PEEC $(30.0 \mu \mathrm{g} / \mathrm{ml})$ and dieckol $(40.0 \mu \mathrm{g} / \mathrm{ml})$ decreased intracellular oxidative stress to $88.9 \%$ and $82.9 \%$ (Fig. 4 B).
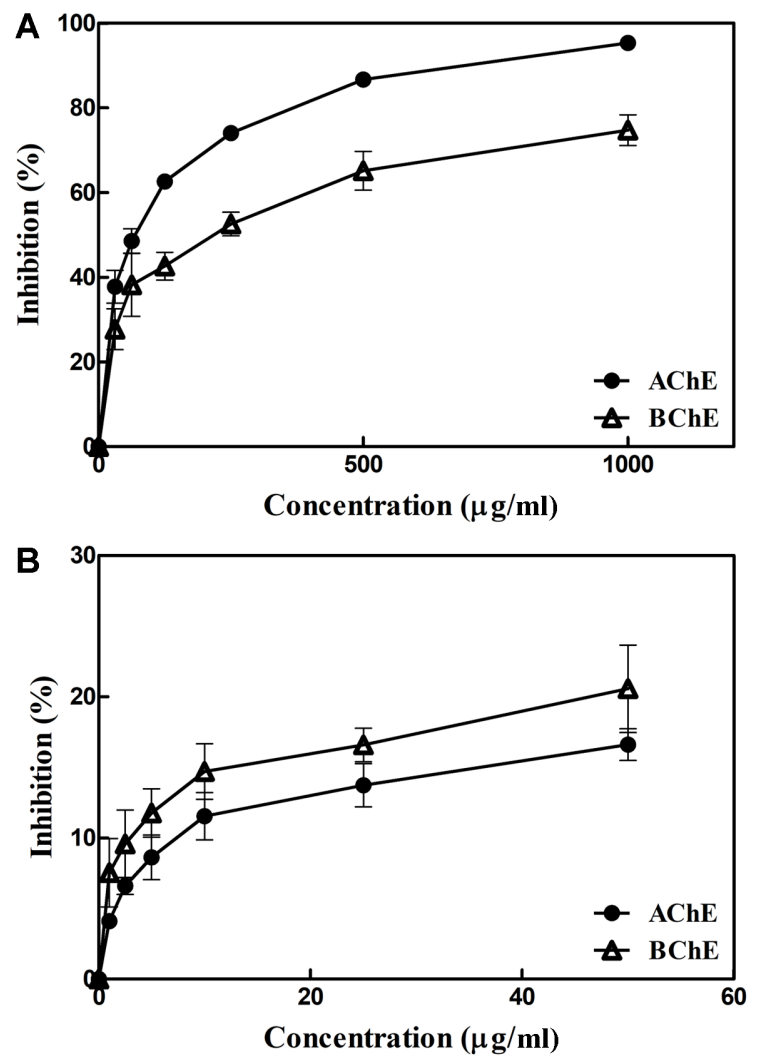

Fig. 5. Inhibitory effects of the (A) phlorotannin-rich extract from Ecklonia cava and (B) dieckol on acetylcholinesterase $(\mathrm{AChE})$ and butyrylcholinesterase (BChE) activities.
Cholinesterase Inhibitory Activity of PEEC and Dieckol

Figure 5A shows that PEEC at various concentrations inhibited the activity of cholinesterases (AChE and $\mathrm{BChE}$ ). At $1,000 \mu \mathrm{g} / \mathrm{ml}$ of PEEC, AChE and BChE inhibition was approximately $95.4 \%$ and $74.7 \%$, respectively, while those at $31.25 \mu \mathrm{g} / \mathrm{ml}$ of PEEC were approximately $37.8 \%$ and $27.8 \%$. The $\mathrm{IC}_{50}$ values of PEEC on inhibition of $\mathrm{AChE}$ and BChE were estimated as $68.9 \mu \mathrm{g} / \mathrm{ml}$ and $217.7 \mu \mathrm{g} / \mathrm{ml}$, respectively.

As shown in Fig. 5B, dieckol at various concentrations inhibited the activity of cholinesterases (AChE and $\mathrm{BChE}$ ). Unlike the results of PEEC inhibitory effects, dieckol showed lower inhibitory effect on $\mathrm{AChE}$ than BChE. At $50.0 \mu \mathrm{g} / \mathrm{ml}$ of dieckol, $\mathrm{AChE}$ and $\mathrm{BChE}$ inhibitions were approximately $16.6 \%$ and $20.6 \%$, respectively. The $\mathrm{IC}_{50}$ values of dieckol on inhibition of $\mathrm{AChE}$ and $\mathrm{BChE}$ could not be determined in the concentration ranges used in this study (Fig. 5B).

\section{Discussion}

The PEEC used in this study was found to contain a large amount of total phenolics (Table 1). EC was reported to show the highest total phenolic content among brown seaweeds [28]. The total phenolic content (810.8 mg GAE/g) of PEEC was about 9.1 times higher than that of the aqueous ethanolic EC extract previously reported by Lee $e t$ al. [13] and about 9.8 times higher than that of the aqueous methanolic EC extract previously reported by Senevirathne et al. [29]. PEEC was extracted using cyclic extraction and continuous centrifugation with high solvent temperature in this study. The higher total phenolic content of PEEC is partly due to different harvest times and extraction methods of EC compared to other studies [13].

Marine algae off the coast of Korea have been reported to show strong antioxidant capacity [30]. EC has been found to have the highest antioxidant capacity among 10 different marine algae [31]. One gram of PEEC used in this study had approximately $23 \%$ higher and $61 \%$ lower antioxidant capacity compared with the same weight of vitamin $C$ by ABTS and DPPH assays, respectively (Table 1). This discrepancy of PEEC antioxidant capacity may be due in part to the use of different radicals and reaction media in each assay [32, 33]. EC has been reported to contain various phlorotannins, including 7-phloroeckol, 6,6'-bieckol, eckol, fucodiphloroethol G, phlorofucofuroeckol A, phloroglucinol, and dieckol [34]. Phlorotannins from marine algae were previously reported to act as antioxidants for scavenging free radicals $[19,35,36]$. 
In addition, we investigated whether PEEC and its component dieckol have neuroprotective effects on neuronal PC-12 and SH-SY5Y cells against oxidative stress caused by hydrogen peroxide. Upon exposure to hydrogen peroxide in PC-12 cells, cell viability was significantly $(p<$ $0.05)$ reduced compared to that of control cells (Fig. 2A). PEEC protected PC-12 and SH-SY5Y cells against oxidative damage (Fig. 2). Pretreatment with PEEC at $62.5 \mu \mathrm{g} / \mathrm{ml}$ significantly $(p<0.05)$ increased PC-12 cell viability by about $30 \%$ compared with cells under oxidative stress only (Fig. 2A). Pretreatment with PEEC at $30.0 \mu \mathrm{g} / \mathrm{ml}$ increased SH-SY5Y cell viability by approximately $19 \%$ compared with cells under oxidative stress only (Fig. 2B). EC extract with antioxidants was previously reported to reduce production and fibrilization of amyloid beta peptide [37, 38]. Phloroglucinol, a building block of phlorotannins such as dieckol, was previously reported to have neuroprotective effects against oxidative stress in SH-SY5Y cells [39]. Phlorofucofuroeckol has been shown to protect PC-12 cells from neurotoxicity induced by glutamate [40]. Dieckol was reported to protect SH-SY5Y cells from oxidative stress and inhibit $\alpha$-synuclein aggregation in SH-SY5Y cells [41]. However, dieckol had no neuroprotective effect in either cell line (Fig. 2). The viability of PC-12 cells treated with dieckol at $40.0 \mu \mathrm{g} / \mathrm{ml}$ was significantly $(p<0.05)$ reduced compared with that of the stress control (Fig. 2A), indicating that higher concentration of dieckol and hydrogen peroxide promote neuronal cell death partly due to pro-oxidant properties.

An increase in intracellular ROS level leads to apoptosis; therefore, removal of ROS using antioxidants such as phlorotannins has neuroprotective effects against oxidative stress. Two sources of oxidative stress, AAPH and $\mathrm{H}_{2} \mathrm{O}_{2}$, increase intracellular oxidative stress in neuronal cells, such as PC-12 and SH-SY5Y cells [42]. Pretreatment of neuronal PC-12 and SH-SY5Y cells with PEEC and dieckol against oxidative stress induced with hydrogen peroxide and AAPH-generated peroxyl radicals attenuated oxidative stress levels inside neurons (Figs. 3 and 4). Phlorotannins such as dieckol from EC have previously been reported to protect hippocampal neuronal HT-22 cells against $\mathrm{H}_{2} \mathrm{O}_{2}$ induced oxidative stress, partly due to inhibition of lipid peroxidation and ROS accumulation [43]. Dieckol has been reported to reduce oxidative stress caused by the neurotoxic rotenone in SH-SY5Y cells [41]. In this study, dieckol reduced oxidative stress in neuronal cell lines, PC-12 and SH-SY5Y, similar to the results of previous reports [41, 43].

PEEC had higher inhibitory activity of AChE than BChE
(Fig. 5A), while dieckol showed higher BChE inhibition than AChE (Fig. 5B). Differences in AChE and BChE inhibitory activities are attributed to different specific binding characteristics of enzyme to substrates such as a single compound (dieckol) and complex PEEC. At similar concentrations, PEEC inhibited AChE and BChE activities more than dieckol (Fig. 5B). Similar to the results of this study, ethanolic extract from EC was reported to exhibit higher AChE inhibitory activity than BChE [44]. Dieckol was previously reported to improve cognitive impairment in ethanol-fed mice, partly due to increased level of acetylcholine and inhibited AChE activity in the brain [45]. It was previously reported that $\mathrm{IC}_{50}$ values of dieckol on $\mathrm{AChE}$ and BChE inhibition were about $17.1 \mu \mathrm{M}$ and $>500$ $\mu \mathrm{M}$, respectively [44]. In this study, $\mathrm{IC}_{50}$ values of dieckol on $\mathrm{AChE}$ and BChE inhibition could not be determined because the concentration used in the enzyme assay was much lower than previously reported $\mathrm{IC}_{50}$ values of $\mathrm{AChE}$ and BChE inhibition [44].

In conclusion, PEEC was determined to contain dieckol, a phlorotannin found in seaweed. PEEC had large amounts of total phenolics and antioxidants. PEEC and dieckol protected neuronal PC-12 and SH-SY5Y cells from intracellular oxidative stress, in part due to their antioxidant capacities. Activities of AChE and BChE were inhibited by PEEC and dieckol, indicating that neurotransmission of acetylcholine can be prolonged in brain neurons. Although dieckol, an indicator component of PEEC, did not significantly increase the neuronal cell viability, other bioactive compounds in PEEC may lead to increased viability in neuronal cells. Our results suggest that PEEC rich in antioxidants can potentially protect neurons from oxidative damage and inhibit hydrolytic activities of cholinesterases. Further research is needed to determine the efficacy in a neurodegenerative animal model in vivo.

\section{Acknowledgments}

This work was supported by a project titled "Development of Global Senior-Friendly Health Functional Food Materials from Marine Resources" funded by the Ministry of Oceans and Fisheries (20170297), Republic of Korea.

\section{Conflict of Interest}

The authors have no financial conflicts of interest to declare. 


\section{References}

1. Scarpini E, Cogiamanian F. 2003. Alzheimer's disease: from molecular pathogenesis to innovative therapies. Expert Rev. Neurother. 3: 619-630.

2. Kovacs GG. 2014. Current concepts of neurodegenerative diseases. EMJ Neurol. 1: 78-86.

3. World Health Organization. 2017. Dementia: a public health priority. Available from https://www.who.int/en/newsroom/fact-sheets/detail/dementia. Accessed on October $9^{\text {th }}$, 2019.

4. Pizzino G, Irrera N, Cucinotta M, Pallio G, Mannino F, Arcoraci V, et al. 2017. Oxidative stress: harms and benefits for human health. Oxid. Med. Cell. Longev. 2017: 8416763.

5. Ježek J, Cooper K, Strich R. 2018. Reactive oxygen species and mitochondrial dynamics: the yin and yang of mitochondrial dysfunction and cancer progression. Antioxidants 7: 13.

6. Tabner BJ, El-Agnaf OMA, Turnbull S, German MJ, Paleologou KE, Hayashi Y, et al. 2005. Hydrogen peroxide is generated during the very early stages of aggregation of the amyloid peptides implicated in Alzheimer disease and familial British dementia. J. Biol. Chem. 280: 35789-35792.

7. Halliwell B. 2012. Free radicals and antioxidants: updating a personal view. Nutr. Rev. 70: 257-265.

8. Panahi Y, Rajaee SM, Johnston TP, Sahebkar A. 2019. Neuroprotective effects of antioxidants in the management of neurodegenerative disorders: a literature review. J. Cell. Biochem. 120: 2742-2748.

9. Soreq H, Seidman S. 2001. Acetylcholinesterase - new roles for an old actor. Nat. Rev. Neurosci. 2: 294-302.

10. Darvesh S, Hopkins DA, Geula C. 2003. Neurobiology of butyrylcholinesterase. Nat. Rev. Neurosci. 4: 131-138.

11. Lee S, Lee D, Baek J, Jung EB, Baek JY, Lee IK, et al. 2017. In vitro assessment of selected Korean plants for antioxidant and antiacetylcholinesterase activities. Pharm. Biol. 55: 22052210.

12. Park SK, Kang JY, Kim JM, Park SH, Kwon BS, Kim G-H, et al. 2018. Protective effect of fucoidan extract from Ecklonia cava on hydrogen peroxide-induced neurotoxicity. J. Microbiol. Biotechnol. 28: 40-49.

13. Lee J-w, Seok JK, Boo YC. 2018. Ecklonia cava extract and dieckol attenuate cellular lipid peroxidation in keratinocytes exposed to PM10. Evid.-Based Compl. Alt. Med. 2018: 8248323.

14. Singh IP, Bharate SB. 2006. Phloroglucinol compounds of natural origin. Nat. Prod. Rep. 23: 558-591.

15. Wijesinghe WAJP, Jeon Y-J. 2011. Exploiting biological activities of brown seaweed Ecklonia cava for potential industrial applications: a review. Int. J. Food Sci. Nutr. 63: 225-235.

16. Le Q-T, Li Y, Qian Z-J, Kim M-M, Kim S-K. 2009. Inhibitory effects of polyphenols isolated from marine alga Ecklonia cava on histamine release. Process Biochem. 44: 168-176.
17. Lee SH, Li Y, Karadeniz F, Kim M-M, Kim S-K. 2009. $\alpha-$ Glucosidase and $\alpha$-amylase inhibitory activities of phloroglucinal derivatives from edible marine brown alga, Ecklonia cava. J. Sci. Food. Agric. 89: 1552-1558.

18. Cho S, Yang H, Jeon Y-J, Lee CJ, Jin Y-H, Baek N-I, et al. 2012. Phlorotannins of the edible brown seaweed Ecklonia cava Kjellman induce sleep via positive allosteric modulation of gamma-aminobutyric acid type A-benzodiazepine receptor: a novel neurological activity of seaweed polyphenols. Food Chem. 132: 1133-1142.

19. Alghazwi M, Kan YQ, Zhang W, Gai WP, Garson MJ, Smid S. 2016. Neuroprotective activities of natural products from marine macroalgae during 1999-2015. J. Appl. Phycol. 28: 3599-3616.

20. Pangestuti R, Kim S-K. 2011. Neuroprotective effects of marine algae. Mar. Drugs 9: 803-818.

21. Kim J, Um M, Yang H, Kim I, Lee C, Kim Y, et al. 2016. Method development and validation fordieckol in the standardization of phlorotannin preparations. Fish. Aquat. Sci. 19: 3 .

22. Singleton VL, Rossi JA, Jr. 1965. Colorimetry of total phenolics with phosphomolybdic-phosphotungstic acid reagents. Am. J. Enol. Vitic. 16: 144-158.

23. Kim D-O, Lee CY. 2004. Comprehensive study of vitamin C equivalent antioxidant capacity (VCEAC) of various polyphenolics in scavenging a free radical and its structural relationship. Crit. Rev. Food Sci. Nutr. 44: 253-273.

24. Brand-Williams W, Cuvelier ME, Berset C. 1995. Use of a free radical method to evaluate antioxidant activity. LWTFood Sci. Technol. 28: 25-30.

25. Heo H-J, Cho H-Y, Hong B, Kim H-K, Kim E-K, Kim B-G, et al. 2001. Protective effect of 4',5-dihydroxy-3',6,7-trimethoxyflavone from Artemisia asiatica against A $\beta$-induced oxidative stress in PC12 cells. Amyloid-J. Protein Fold. Disord. 8: 194-201.

26. Wolfe KL, Liu RH. 2007. Cellular antioxidant activity (CAA) assay for assessing antioxidants, foods, and dietary supplements. J. Agric. Food Chem. 55: 8896-8907.

27. Ellman GL, Courtney KD, Andres V, Jr., Featherstone RM. 1961. A new and rapid colorimetric determination of acetylcholinesterase activity. Biochem. Pharmacol. 7: 88-95.

28. Heo S-J, Park E-J, Lee K-W, Jeon Y-J. 2005. Antioxidant activities of enzymatic extracts from brown seaweeds. Bioresour. Technol. 96: 1613-1623.

29. Senevirathne M, Kim S-H, Siriwardhana N, Ha J-H, Lee KW, Jeon Y-J. 2006. Antioxidant potential of Ecklonia cava on reactive oxygen species scavenging, metal chelating, reducing power and lipid peroxidation inhibition. Food Sci. Technol. Int. 12: 27-38.

30. Lee J-H, Kim G-H. 2015. Evaluation of antioxidant activity of marine algae-extracts from Korea. J. Aquat. Food Prod. Technol. 24: 227-240. 
31. Shin D-B, Han E-H, Park S-S. 2014. Cytoprotective effects of Phaeophyta extracts from the coast of Jeju island in HT-22 mouse neuronal cells. J. Korean Soc. Food Sci. Nutr. 43: 224-230.

32. Kim D-O, Lee KW, Lee HJ, Lee CY. 2002. Vitamin C equivalent antioxidant capacity (VCEAC) of phenolic phytochemicals. J. Agric. Food Chem. 50: 3713-3717.

33. Yoo KM, Kim D-O, Lee CY. 2007. Evaluation of different methods of antioxidant measurement. Food Sci. Biotechnol. 16: 177-182.

34. Li Y, Qian Z-J, Ryu B, Lee S-H, Kim M-M, Kim S-K. 2009. Chemical components and its antioxidant properties in vitro: an edible marine brown alga, Ecklonia cava. Bioorg. Med. Chem. 17: 1963-1973.

35. Kang HS, Chung HY, Jung JH, Son BW, Choi JS. 2003. A new phlorotannin from the brown alga Ecklonia stolonifera. Chem. Pharm. Bull. 51: 1012-1014.

36. Shibata T, Ishimaru K, Kawaguchi S, Yoshikawa H, Hama Y. 2008. Antioxidant activities of phlorotannins isolated from Japanese Laminariaceae. J. Appl. Phycol. 20: 705-711.

37. Kang I-J, Jeon YE, Yin XF, Nam J-S, You SG, Hong MS, et al. 2011. Butanol extract of Ecklonia cava prevents production and aggregation of beta-amyloid, and reduces beta-amyloid mediated neuronal death. Food Chem. Toxicol. 49: 2252-2259.

38. Kang IJ, Jang BG, In S, Choi B, Kim M, Kim MJ. 2013. Phlorotannin-rich Ecklonia cava reduces the production of beta-amyloid by modulating alpha- and gamma-secretase expression and activity. NeuroToxicology 34: 16-24.
39. Kim HS, Lee K, Kang KA, Lee NH, Hyun JW, Kim H-S. 2012. Phloroglucinol exerts protective effects against oxidative stress-induced cell damage in SH-SY5Y cells. J. Pharmacol. Sci. 119: 186-192.

40. Kim J-J, Kang Y-J, Shin S-A, Bak D-H, Lee JW, Lee KB, et al. 2016. Phlorofucofuroeckol improves glutamate-induced neurotoxicity through modulation of oxidative stress-mediated mitochondrial dysfunction in PC12 cells. PLoS One 11: e0163433.

41. Cha S-H, Heo S-J, Jeon Y-J, Park SM. 2016. Dieckol, an edible seaweed polyphenol, retards rotenone-induced neurotoxicity and $\alpha$-synuclein aggregation in human dopaminergic neuronal cells. RSC Adv. 6: 110040-110046.

42. Othman SB, Yabe T. 2015. Use of hydrogen peroxide and peroxyl radicals to induce oxidative stress in neuronal cells. Rev. Agric. Sci. 3: 40-45.

43. Kang S-M, Cha S-H, Ko J-Y, Kang M-C, Kim D, Heo S-J, et al. 2012. Neuroprotective effects of phlorotannins isolated from a brown alga, Ecklonia cava, against $\mathrm{H}_{2} \mathrm{O}_{2}$-induced oxidative stress in murine hippocampal HT22 cells. Environ. Toxicol. Pharmacol. 34: 96-105.

44. Yoon NY, Chung HY, Kim HR, Choi JS. 2008. Acetyl- and butyrylcholinesterase inhibitory activities of sterols and phlorotannins from Ecklonia stolonifera. Fish. Sci. 74: 200-207.

45. Myung C-S, Shin H-C, Bao HY, Yeo SJ, Lee BH, Kang JS. 2005. Improvement of memory by dieckol and phlorofucofuroeckol in ethanol-treated mice: possible involvement of the inhibition of acetylcholinesterase. Arch. Pharm. Res. 28: 691-698. 